\title{
Desafios da Intersetorialidade na Implementação de Programa de Prevenção ao Uso Abusivo de Drogas
}

\author{
Girlane Mayara Peres \\ Universidade Federal de Santa Catarina, SC, Brasil. \\ Tania Maris Grigolo \\ Complexo de Ensino Superior de Santa Catarina, \\ SC, Brasil. \\ Daniela Ribeiro Schneider \\ Universidade Federal de Santa Catarina, SC, Brasil.
}

Resumo: Este artigo possui como objetivo conhecer as percepções dos profissionais e gestores da saúde e educação sobre os desafios da articulação intersetorial para a implantação de um programa de prevenção ao uso de drogas. Faz parte da avaliação de processo de um projeto maior de avaliação de programas preventivos baseados em evidência em procedimento de adaptação para a realidade brasileira. Com base em uma abordagem qualitativa, teve delineamento exploratório e descritivo, envolvendo entrevistas semiestruturadas e grupos focais com 18 profissionais e gestores dos setores da educação e saúde do município de Florianópolis, envolvendo três escolas e três unidades básicas de saúde. Utilizou-se análise de conteúdo para o tratamento dos dados. Os resultados indicam que os profissionais perceberam que a necessidade de criar estratégias conjuntas de intervenção para a implementação do programa foi algo positivo, que contribuiu para a aproximação da saúde com o espaço escolar, indicando que a ação conjunta possibilitou ampliar o cuidado às famílias que procuravam a UBS e facilitou o acesso integral aos educandos. Os entrevistados identificaram, por outro lado, algumas dificuldades para a atuação conjunta, tais como o atravessamento de questões políticas, a personalização das relações intersetoriais, as dificuldades para se compreender o significado de intersetorialidade na prática cotidiana dos serviços e as excessivas demandas cotidianas de trabalho que impedem o envolvimento dos profissionais em novos projetos. O desafio da implementação conjunta de ações no programa preventivo mobilizou os setores e pode significar um estímulo à aproximação intersetorial para se debruçar sobre o complexo tema dos problemas relacionados ao uso de drogas.

Palavras-chave: Ação intersetorial, Drogas, Prevenção primaria, Adolescente, Saúde escolar, Avaliação de programas e Projetos de saúde. 


\title{
Challenges of the Intersectoral Approach in the Implementation of a Program for the Prevention of Drug Abuse
}

\begin{abstract}
This article aims to know the perceptions of professionals and managers of health and education on the challenges of intersectoral coordination for the implementation of a drug prevention program. It is part of the evaluation of processes of one larger project of evaluation of preventive programs based on evidences, in process of adaptation to the Brazilian reality. Based on a qualitative approach, this study has an exploratory and descriptive design, with semi-structured interviews and focus groups with 18 professionals and managers of the education and health sectors of the municipality of Florianopolis, including three schools and three basic health units (UBS). Content analysis was used for the treatment of the data. The results show that the professionals perceived that the need to establish joint strategies for the implementation of the program was something positive that contributed to approaching health within the school space, showing that the joint action made possible to extend the care to families seeking the UBS and provided comprehensive access to the students. On the other hand, respondents identified some difficulties in joint activities, such as political issues, customization of intersectoral relationships, difficulties to understand the meaning of the intersectoral approach in the daily practice of services, excessive demands of work that stop the involvement of professionals in new projects. The challenge of the joint implementation of actions in the preventive program mobilized the sectors and can mean a stimulus so that the intersectoral approach tackles the complex issue of the problems related to drug use.
\end{abstract}

Keywords: Intersectoral action, Illegal drugs, Primary prevention, Adolescent, School health, Program Evaluation.

\section{Desafíos del Enfoque Intersectorial en la Implementación de un Programa de Prevención del Uso Abusivo de Drogas}

Resumen: Este artículo tiene como objetivo conocer las percepciones de profesionales y gestores de la salud y educación sobre los retos de la coordinación intersectorial para la implementación de un programa de prevención del uso de drogas. Forma parte de la evaluación de procesos de un proyecto mayor de evaluación de programas preventivos basados en evidencias, en proceso de adaptación a la realidad brasileña. Basado en un enfoque cualitativo, posee un diseño exploratorio y descriptivo, con entrevistas semiestructuradas y grupos focales con 18 profesionales y gestores de los sectores de educación y salud del municipio de Florianópolis, abarcando tres escuelas y tres unidades básicas de salud (UBS). Se utilizó análisis de contenido para el tratamiento de los datos. Los resultados indican que los profesionales percibieron que la necesidad de establecer estrategias conjuntas para la implementación del programa fue algo positivo, que contribuyó a aproximar la salud con el espacio escolar, lo que indica que la acción conjunta hizo posible extender la atención a las familias que buscaban la UBS y facilitó el acceso integral a los estudiantes. Los entrevistados identificaron, por otra parte, algunas dificultades para las actividades conjuntas, tales como cuestiones políticas, personalización de las relaciones intersectoriales, dificultades para comprender el significado del enfoque intersectorial en la práctica diaria de los servicios, las excesivas demandas de trabajo diarias que impiden el envolvimiento de los profesionales en nuevos proyectos. El reto de la implementación conjunta de acciones en el programa preventivo movilizó a los sectores y puede significar un estímulo para que el enfoque intersectorial aborde la compleja cuestión de los problemas relacionados al uso de drogas.

Palabras claves: Acción intersectorial, Drogas ilegales, Prevención primaria, Adolescente, Salud escolar, Evaluación de Programas y Proyectos de Salud. 


\section{Introdução}

A importância da implementação de uma política de prevenção sistemática ao uso de álcool e outras drogas $(\mathrm{AD})$ no Brasil, que supere a lógica de ações pontuais e desarticuladas, baseadas somente em informações amedrontadoras sobre o problema e no proibicionismo, está em franco debate, sendo que vêm se desenvolvendo nos últimos anos mudanças nas estratégias de implementação de programas preventivos, em direção a um novo modelo ainda em construção. Tal modelo possui base, no mais das vezes, na lógica da redução de danos (Canoletti, \& Soares, 2005) e em indicadores internacionais de eficácia (Sloboda, \& Petras, 2014), entre os quais, a valorização das habilidades de vida, as informações baseadas na ciência, o fortalecimento dos contextos relacionais das pessoas, a utilização de metodologias interativas e a articulação intersetorial em sua implementação, visando a saúde e o bem-estar.

Os avanços na qualificação da prevenção passam também por um melhor entendimento da epidemiologia do uso da substância, principalmente quando esta indica o risco do consumo precoce e a predição da progressão linear do uso, informações que, quando tomada por base do planejamento, tornam as ações melhor direcionadas e precisas (Sloboda et al., 2009). Nesta direção, verifica-se que no Brasil as ações preventivas fazem-se necessárias, dada a magnitude do problema do consumo entre adolescentes, como se pode identificar na Pesquisa Nacional de Saúde do Escolar (Pense), realizada com alunos do $9^{\circ}$ ano de escolas públicas, que constatou que $66,6 \%$ dos escolares já haviam experimentado a bebida alcoólica, sendo esse indicador maior na Região Sul $(76,9 \%)$ (Instituto Brasileiro de Geografia e Estatística, 2013). O consumo de bebida alcoólica entre os escolares, avaliado pelo consumo feito nos 30 dias que antecederam a pesquisa, foi de $26,1 \%$ no Brasil e não apresentou diferenças relevantes entre os sexos masculino $(25,2 \%)$ e feminino $(26,9 \%)$. Em relação às drogas ilícitas, $7,3 \%$ dos educandos já as utilizaram pelo menos uma vez na vida, e o maior percentual entre as capitais foi em Florianópolis, com 17,5\% (IBGE, 2013).

Os dados acima complementam estudo de maior abrangência, desenvolvido em 2010, o VI Levantamento Nacional sobre o consumo de drogas psicotrópicas entre os estudantes de ensino fundamental e médio nas 27 capitais brasileiras, no qual aparece que as drogas mais utilizadas pelos estudantes foram as lícitas, bebidas alcoólicas e tabaco, respectivamente $60,5 \%$ e $16,9 \%$ para uso na vida e $42,4 \%$ e $9,6 \%$ para uso no ano. Destacaram-se também o uso no ano de energéticos em mistura com álcool $(15,4 \%)$, os inalantes $(5,2 \%)$, a maconha $(3,7 \%)$, os ansiolíticos $(2,6 \%)$, a cocaína $(1,8 \%)$ e os anfetamínicos $(1,7 \%)$ (Carlini et al., 2010). Esses dados, principalmente referentes ao uso no ano, também indicam o crescente consumo precoce, principalmente, de álcool e tabaco entre adolescentes, reforçando a necessidade de ações preventivas para esta faixa etária.

Outros fatores também corroboram com a necessidade de investimento em projetos de prevenção, tais como as mudanças em curso na área da saúde no Brasil, que apontam para a necessidade de superação dos modelos focados somente na direção curativa, implicando na consolidação de uma concepção ampliada em saúde e envolvendo a integração de diferentes níveis de ação: promoção, prevenção, tratamento e reabilitação. Nesse sentido, as diretrizes da Política Nacional de Humanização da Saúde, organizadas em 2003, que visam qualificar o modo de se fazer saúde com corresponsabilidade e intersetorialidade, implicaram a proposição de modalidades de atenção que rompam com reducionismos e amplie seu olhar e suas estratégias de ações (Brasil, 2006). Do mesmo modo, a política de atenção integral aos usuários de drogas, do Ministério da Saúde (MS), trouxe para o campo do cuidado dessa população os pressupostos da reforma sanitária e da reforma psiquiátrica, envolvendo também ações de prevenção (Brasil, 2003). Já em 2011, o Plano “Crack é possível vencer”, buscou construir uma política pública para o campo $\mathrm{AD}$ pautada neste olhar ampliado e de caráter intersetorial, tendo um dos seus eixos a prevenção e cujo macroprojeto do MS, referido aqui neste artigo, foi uma das principais ações.

É importante destacar o Programa Saúde na Escola (PSE), proposto em dezembro de 2007, que se consolida como política pública intersetorial já em seu nascedouro, pois prevê a articulação entre os Ministérios da Saúde e da Educação para a realização de ações integradas. Tem como principal objetivo articular as equipes de saúde da Atenção Básica e profissionais de educação das escolas do mesmo território para o desenvolvimento de ações de prevenção de risco e danos e promoção da saúde no contexto do cuidado e da educação integrais, estando previsto em seu bojo a prevenção ao uso de drogas (Figueiredo, Machado, \& Abreu, 2010). 
Sendo assim, a intersetorialidade é uma das prerrogativas contemporâneas em políticas públicas, na medida em que é compreendida em termos práticos como uma estratégia para intervir em fenômenos que são complexos em sua constituição, como são os fenômenos de saúde em geral e seus determinantes sociais (Andrade, 2006).

A intersetorialidade parte do pressuposto de que as instituições envolvidas apresentem objetivos comum, porém cada uma tendo ações que partem de campos de atuação diferentes, sendo que cada campo deve questionar sobre o lugar a partir do qual está autorizado a intervir (Schneider et al., 2016). Neste sentido, a intersetorialidade propicia a reestruturação e reunião de vários saberes, atores e setores, tornando a compreensão e as ações complexas e com mais chance de obterem bons resultados (Paula, Palha \& Protti, 2004). Desde o momento em que cada setor dialoga e interage com o outro, algo novo é construído nesta relação e essa construção produz mudanças na própria instituição e nas demais em que se relacionam (McNamee, 2010).

Entretanto, alguns autores têm chamado a atenção dos desafios da consolidação da intersetorialidade, uma vez que cada um dos setores envolvidos possui a sua especificidade, em termos culturais, de responsabilidades, de políticas, de burocracias e fluxos, sendo a relação entre cada um deles é singular (McNamee, 2010). Tais desafios se consolidam no que Andrade (2006) chama de "dilema da intersetorialidade", pela contradição existente entre experiências intersetoriais ainda isoladas e políticas públicas "hegemonicamente setorializadas" (Andrade, 2006, p. 284).

O espaço da escola, como um lugar de ocorrência de múltiplos acontecimentos de vida, com a complexidade do que envolve o processo de ensino-aprendizagem, é um ambiente propício aos desafios intersetoriais.

Segundo a Organização Pan-americana de Saúde (Organização Panamericana de la Salud, 2001), a escola é o local mais adequado para o desenvolvimento de ações preventivas visto que possui acesso diário de crianças e adolescentes, acompanha-os durante, pelo menos, um período do dia e alguns anos de sua vida, possui contato com o padrão familiar dos educandos e é um lugar de ocorrência de múltiplos acontecimentos de vida, com a complexidade do que envolve o processo de ensino-aprendizagem. Nesse sentido, a Secretaria Nacional de Políticas sobre Drogas (Senad) tem ofertado diferentes cursos de ensino a distância que visam a capacitação dos profissionais da educação e saúde sobre drogas e prevenção, como, por exemplo, no "Curso Prevenção do Uso de Drogas para Educadores de Escolas Públicas”.

Em relação à educação, destaca-se a importância de uma política pedagógica que busque aproximação com os educandos considerados como sujeitos integrais, valorizando espaços de acolhimento, aconselhamento e vínculos em detrimento de punições como suspensão e expulsão. Ressalta-se também a inclusão das estratégias de prevenção desenvolvidas pelos próprios profissionais da escola, que são adultos de referência para as crianças e adolescentes e, portanto, se colocam como mediações para um ambiente de proteção aos jovens.

Da mesma forma, é importante incluir o enfoque de habilidades de vida no currículo das escolas, já que há indicadores internacionais consistentes da eficácia dessa abordagem (Instituto Nacional sobre el Abuso de Drogas, 2004). A Organização Mundial da Saúde (OMS) e a Organização Pan-Americana da Saúde (OPAS), no início dos anos 2000, passaram a indicar a realização de programas de prevenção ao uso de drogas baseados em habilidades de vida (Paiva, \& Rodrigues, 2008), na medida em que estas implicam o desenvolvimento das seguintes características: o autoconhecimento, ou seja, a identificação e compreensão de seus próprios sentimentos, vontades, emoções; a empatia, ou capacidade de se colocar no lugar do outro; a capacidade de comunicação, implicando a habilidade de se expressar com clareza e de escutar ao outro; habilidades interpessoais, implicando a capacidade de iniciar e manter, assim como a capacidade de lidar com situações difíceis ou tensas de forma construtiva sem prejudicar outras pessoas; além das habilidades cognitivas, de pensamento criativo, reflexão crítica.

Outras habilidades que também podem ser desenvolvidas são as capacidades de: avaliar as consequências, riscos e benefícios de sua escolha e buscar alternativas a partir dos recursos pessoais e experiências que possui, de questionar e não aceitar os acontecimentos, uma vez que faz uma análise a partir das evidências, razões e suposições, entre outros. As habilidades de vida são consideradas fatores de proteção, pois favorecem o bem-estar, possibilitam o aumento da comunicação assertiva e resiliência, 
o que contribui para a diminuição da incidência e prevalência do uso de drogas entre os adolescentes (Paiva, \& Rodrigues, 2008).

A experiência aqui analisada diz respeito a implementação de um programa preventivo ao uso de drogas baseado em evidência, focados em habilidades de vida, de origem europeia, o Unplugged, desenvolvido pelo MS, com vistas à sua adaptação cultural à realidade brasileira. Tal programa nasceu na esfera da saúde, especificamente na Coordenação Geral de Saúde Mental, Álcool e Outras Drogas do Ministério da Saúde, mas se concretizou intersetorialmente a partir das relações entre as Secretarias Municipais de Saúde e de Educação dos municípios participantes do projeto. O objeto principal da ação articulada foi uma de suas ações, a Oficina dos Pais, prevista para ser realizada de maneira integrada entre o setor saúde e educação do território de cada escola participante.

Dessa maneira, como foco deste artigo, a intersetorialidade é prevista na implementação brasileira do programa de prevenção estudado, enquanto desafio para a consolidação de políticas públicas mais efetivas, ao buscarem construir ações preventivas compartilhadas entre a educação e a saúde, em um tema cuja complexidade exige diferentes olhares, como é o caso vulnerabilidade psicossocial e uso de drogas.

Para a Atenção Psicossocial e a Educação Integral, como princípios norteadores das políticas públicas no campo da Saúde Mental e Educação, a construção contínua da rede intersetorial é essencial, pois, na base da inserção social dos usuários ou da aprendizagem significativa dos educandos estão os recursos existentes na comunidade, os quais são fatores de proteção ao uso de drogas. Assim sendo, esses recursos comunitários precisam dialogar entre si, para que os sujeitos possam experimentar-se incluídos e acolhidos em suas redes sociais e no território (Martinhago, \& Oliveira, 2012)

\section{Aspectos metodológicos}

\section{Sobre o Programa Preventivo em avaliação}

Este artigo é parte do resultado da dissertação de Mestrado Profissional em Saúde Mental e Atenção Psicossocial - Universidade Federal de Santa Catarina (MPSM - UFSC) intitulada "Processo de implantação de um programa de prevenção ao uso de drogas: o desafio de uma rede intersetorial", vinculado ao macroprojeto realizado pela Coordenadoria Geral de Saúde Mental, Álcool e outras Drogas do Ministério da Saúde, inicialmente desenvolvido em parceria com o Escritório das Nações Unidas para Drogas e Crimes (UNODC) e, posteriormente, somado às ações conjuntas com a Senad, do Ministério da Justiça. O projeto traz um pioneirismo para a área de álcool e outras drogas no Brasil, na medida em que planeja a implantação de uma política pública com foco na prevenção em larga escala, mas baseada em evidências e que se sustenta em estudos que acompanham seu processo de implementação e adaptação cultural e avalia o processo e a efetividade das ações desenvolvidas, num processo colaborativo entre os órgãos executivos, responsáveis pela implantação dos programas e as universidades, responsáveis pela avaliação destes, sendo elas a Universidade Federal de São Paulo (Unifesp) e a UFSC, em parceria com o Complexo de Ensino Superior de Santa Catarina (Cesusc).

Alguns resultados do projeto guarda-chuva, executado em 2013, ao qual este subprojeto pertence, já foram publicados, com destaque ao de avaliação geral do processo de implementação (Medeiros, Cruz, Schneider, Sanudo, \& Sanchez, 2016) e o de avaliação da eficácia do estudo quasi-experimental, então desenvolvido (Sanchez et al., 2016),

A proposta da articulação intersetorial entre as escolas públicas e as Unidades Básicas de Saúde (UBS) foi implementada, em 2013, pela Coordenação Geral de Saúde Mental, Álcool e outras Drogas do Ministério da Saúde em combinação com a gestão municipal. Para a execução e implantação nas escolas, o programa contou com o acompanhamento de multiplicadoras, contratadas pelo Ministério da Saúde e que atuavam como apoio aos professores e aos profissionais da saúde envolvidos (Medeiros et al., 2016). Sendo assim, a materialização do programa só foi possível em função das relações e pactuações entre diversos setores da gestão federal, estadual e municipal das políticas de saúde e educação com seus respectivos programas e serviços, tais como UBS, escolas públicas e PSE.

O programa analisado neste artigo é conhecido como Unplugged e foi desenvolvido inicialmente em um estudo multicêntrico envolvendo sete países europeus, coordenado pelo European Drug Addiction Prevention Trial (Eudap) e, posteriormente, aplicado também em países da Ásia e África, sempre demonstrando evidências em sua avaliação (Faggiano, 
Richardson, Bohm, \& Galanti, 2007; Faggiano et al., 2010). O programa foi renomeado, fruto desta experiência de adaptação à realidade brasileira em 2013, com o nome escolhido pelos adolescentes participantes, como \#tamojunto.

O modelo lógico do referido programa de prevenção prevê o desenvolvimento de habilidades de vida, de informações críticas sobre drogas e intervenção em crenças normativas entre os adolescentes. Realizado em 12 aulas com educandos de sexto ao oitavo ano (11 a 14 anos), foi aplicado pelos próprios professores em classes regulares de escolas públicas. Cada aula possui um tema, conteúdo e metodologia pré-estabelecidos pelo programa original.

Foram organizadas, ainda, três Oficinas com Pais, que versaram sobre o tema da adolescência que foram baseadas em habilidades de vida e crenças normativas. Essas oficinas tinham como prerrogativa ser planejadas e realizadas por profissionais da escola envolvidos no programa preventivo e por profissionais da saúde do território adstrito da escola. As oficinas previam atividades com os pais, com os adolescentes e, depois, atividades conjuntas entre pais e adolescentes, com base na lógica metodológica do programa.

Foram estas oficinas o objeto de estudo principal do presente trabalho, que através delas buscou investigar as percepções dos profissionais no que se refere à experiência da articulação intersetorial realizada na implementação piloto do Unplugged, em 2013.

\section{Delineamento da pesquisa}

A metodologia do presente projeto teve um caráter qualitativo, visando desvelar os significados e intencionalidades relacionados ao fenômeno social em estudo (Minayo, 1999). Fizeram parte deste estudo três escolas municipais e três UBS no município de Florianópolis - SC. Foram utilizadas entrevistas semiestruturadas e grupos focais, ambos com roteiro previamente definido, que envolveram os participantes na ação direta nas escolas, principalmente os que participaram das oficinas dos pais do Programa Unplugged e os gestores municipais de saúde e educação. Foram realizadas 14 entrevistas e dois grupos focais com 18 participantes. As entrevistas foram realizadas com seis profissionais da saúde, seis profissionais da educação, sendo três articuladores do PSE e três gestores municipais, sendo um da coordenação nacional da saúde mental, um da coordenação municipal de saúde e um da coordenação da educação, assim como dois multiplicadores. Os grupos focais foram com professores envolvidos no projeto e com gestores municipais da educação do município.

Os dados categorizados foram analisados por meio da técnica de análise de conteúdo, que se constitui uma pré-análise em que ocorre a leitura exaustiva dos dados, a exploração do material criando as subcategorias, após as categorias, e, por último, o tratamento dos resultados e a interpretação das informações (Bardin, 2009).

O projeto foi aprovado pelo Comitê de Ética em Pesquisa da UFSC sob número 711.377 e atendeu a resolução 466 do Conselho Nacional de Saúde.

\section{Resultados e discussão}

\section{A construção da relação intersetorial no território}

O território, enquanto espaço vivo, é constituído por espaços físicos, dimensões sociais, políticas e econômicas, normas, crenças, culturas das pessoas que nele habitam, heranças históricas e todas essas dimensões se articulam e conversam produzindo novos saberes e formas de ser e constituir-se. É a partir do território que as ações em saúde são planejadas, uma vez que ele é o organizador da rede de atenção à saúde e deve orientar as ações dos serviços públicos (Brasil, 2004).

Neste sentido, todo projeto de intervenção deve ser pensado para e a partir do território, conforme a fala de um dos entrevistados:

Primeiro a importância eu acho que é ter claro
que a gente tá falando de território. Que é a pala-
vra que mais se fala. Então, você não tá fazendo
um trabalho pra escola ou um trabalho pra Uni-
dade Básica de Saúde, você está fazendo um tra-
balho pro território. Acho que essa é a primeira
importância.E Eepois pensar numa estratégia que
realmente induzisse essa relação (Profissional da
Gestão Federal).

Para entender o território e a intersetorialidade, utilizou-se o modelo bioecológico. Nele os processos psicológicos são propriedades do sistema e a pessoa é um dos elementos em que o foco principal são os processos e as interações. Em relação ao contexto, ele pode ser compreendido como estrutu- 
ras encaixadas uma dentro da outra. No nível mais interno está o ambiente imediato, que contém a pessoa em desenvolvimento. Esse ambiente, também chamado de microssistema, é onde a pessoa está ou frequenta, como a casa ou a sala de aula. A próxima estrutura, identificada como mesossistema, são as conexões entre os ambientes imediatos, por exemplo, a relação entre os profissionais da escola e os pais, assim, a capacidade de um educando aprender a ler depende tanto de como ele é ensinado quanto da existência e natureza de laços entre a escola e a família (Bronfenbrenner, 1996).

No nível seguinte, o exossistema, percebe-se que "o desenvolvimento da pessoa é profundamente afetado pelos eventos que ocorrem em ambientes nos quais a pessoa nem sequer está presente" (Bronfenbrenner, 1996, p. 5). Portanto, a relação que os profissionais da escola têm com os profissionais da UBS, mesmo que a criança não frequente esta última, interfere no seu desenvolvimento. Por último, todos esses três níveis estão inseridos dentro de algo mais amplo, como a cultura e regras de comportamento e sociais, identificados como macrossistema (Bronfenbrenner, 1996).

O território e o contexto onde as instituições estão inseridas são vivos, dinâmicos, produtos e produtores de fenômenos psicossociais, desse modo, a partir da fala do profissional da gestão federal, é possível identificar que o território é um espaço de produção de saúde, e torna-se mais potente mediante a relação intersetorial. Essa forma de perceber amplia o paradigma da saúde, pois vai além das ações individuais da UBS, da escola, ou dos profissionais. Esse novo olhar para o território é complexo e dinâmico, pois são necessárias diversas relações intersetoriais para se pensar e cuidar de forma contextualizada. Tais relações envolvem os serviços públicos, privados e civis e as diversas hierarquias dentro desses segmentos.

Para o fortalecimento do território, o MS utilizou a estratégia da aproximação com políticas e programas já existentes nos municípios, tais como o PSE. O PSE possibilitou o acesso da Equipe de Saúde à escola e facilitou o diálogo entre os dois setores. Porém, mesmo com essa estratégia de aproximação, algumas dificuldades foram sentidas, pois dentro dos programas já anteriormente realizados o "dilema da intersetorialidade" (Andrade, 2006) se apresentava, na medida em que muitas das ações do PSE, acabavam sendo a visita da saúde dentro da escola, mas não necessariamente a articulação das ações entre as instituições.

Desse modo, houve destaque, na fala dos profissionais da saúde e educação, sobre a importância da implementação do Programa Unplugged ter "forçado" o diálogo intersetorial, por ter viabilizado meios de realizá-lo na prática cotidiana, como foi o caso da participação do multiplicador na construção da articulação intersetorial entre a UBS e a escola. O papel do multiplicador foi fomentar, organizar, estimular essas instituições a se aproximar e conversar.

Então, acho que essa proximidade com a multiplicadora, com a diretora, mas principalmente, com a multiplicadora foi fundamental. Eu acho que ela é uma pessoa fundamental, essa pessoa que une as pontas, né? Ela faz os laços. Pra início é uma figura importante. Tem que ter alguém que faça essa união, uma figura de fora, completamente neutra e que faça essa união. E que não seja uma pessoa específica pra cada local, mas que tenha essa função de fazer esses laços (Profissional da saúde).

A estratégia de inclusão de uma multiplicadora do programa foi avaliada como positiva para a construção da intersetorialidade, pois o trabalho de articulação, por vezes, tem sido difícil para os profissionais, tendo em vista a disponibilidade de tempo para esse fim e as inúmeras dúvidas de como iniciar essa aproximação e construir a relação. Quando há uma pessoa dedicada a esse propósito de auxiliar e provocar essa relação, esse é um elemento facilitador.

Porque é importante, eu sinto que o meu papel é muito mais de otimizar os encontros, não de realizar. $O$ fato de ter um terceiro, dizendo que os dois têm que vir, isso otimiza, isso faz acontecer. Tem que ter alguém nessa função, não necessariamente alguém de fora. Acho que tem se pensado muito na ideia de que seja alguém de dentro e acho que faz todo sentido que seja alguém de dentro. Mas acho que sem ninguém pra isso, acho que volta muito para uma ideia fragmentada de trabalho, "eu faço a minha parte, tu faz a tua e de vez em quando a gente senta para dar uma conversadinha pra saber o que eu fiz e o que tu fez". Mas fica muito da intervenção da saúde e 
intervenção da educação e não uma coisa intersetorial (Multiplicador do programa).

$\mathrm{Na}$ intersetorialidade deve haver a corresponsabilização e as parcerias entre as instituições, em busca da resolutividade das demandas dos serviços. Para exemplificar, segue a Figura. Nela o território é representado pelo quadrado, pois ele delimita uma área, os círculos são dois serviços que pertencem ao território, a parte em cinza é a relação intersetorial, ou seja, o que é feito em conjunto. As setas são as relações entre os serviços e o território e os demais serviços. $\mathrm{Na}$ matemática, a intersecção entre dois elementos significa que há um conjunto de elementos que, simultaneamente, pertencem aos dois conjuntos. Se pensar que um conjunto é a saúde e o outro é a educação, pode-se supor que ambos possuem objetos e fenômenos em comum, pois estão no mesmo território e ambientes.

A intersecção entre a UBS e a educação forma uma espécie de novo lócus, que se sustenta na comunicação com a saúde, com a educação e com o território, além de criar suas próprias regras, culturas, estilos etc. Portanto, os multiplicadores possibilitaram e contribuíram para que tal interseção e construções conjuntas fossem realizadas.

O multiplicador possuía como função possibilitar aos serviços esse primeiro passo na construção de diálogo e rede intersetorial e, assim, os profissionais, ao se apropriarem dessas funções, aos poucos não necessitarem mais do multiplicador. Contudo, se para os profissionais da escola e UBS a intersetorialidade não fizer sentido, isso pode ser um risco a essa relação e um obstáculo para a continuidade da atividade conjunta.

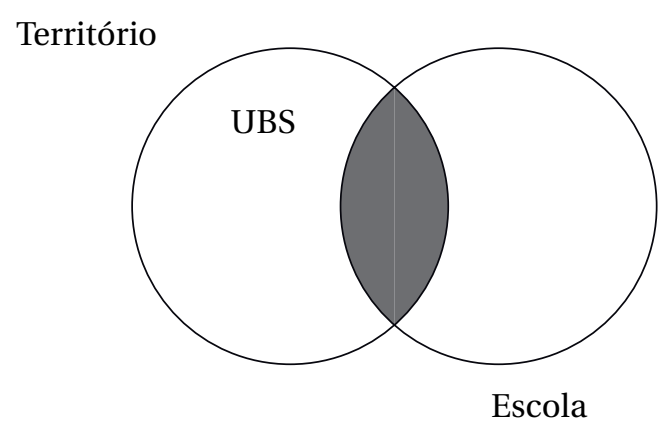

Fonte: Elaboração das autoras (2014).

Figura

Intersecção entre saúde e educação.
A promoção da relação intersetorial no território, a partir do programa de prevenção, ocorreu desde a formação dos profissionais. Ela foi realizada em dois dias, em que estavam presentes os profissionais da educação e da saúde. Foi ministrada pelos multiplicadores, os quais apresentaram a proposta do programa, capacitaram para a realização das 12 aulas, Oficina de Pais e tiraram as dúvidas dos participantes. Nesse encontro, como estavam presentes os profissionais de ambos os setores, realizou-se o primeiro contato, a apresentação de cada participante, identificação e o reconhecimento das pessoas, as primeiras conversas e vínculos e o início das pactuações.

Como se estava criando uma nova forma de se relacionar, qual seja, a intersetorial, formada por um grupo de pessoas corresponsáveis pela aplicação de um programa de prevenção, era essencial que todos os profissionais recebessem as informações conjuntamente. Desse modo, a relação intersetorial se construiu, desde o início, de forma compartilhada e coletiva.

Foi identificada na fala dos entrevistados, que a disponibilidade do profissional para se articular com outro setor contribuía para a construção intersetorial.

Uma coisa da saúde que motivou muito, principalmente a equipe do NASF [Núcleos de Apoio à Saúde da Família] e pelo fato da enfermeira ser jovem no posto, tem muito "tesão" pelo trabalho, então tudo pode ser uma possibilidade. Não tem aquela coisa institucionalizada de que não dá certo, de que não é assim (Multiplicador do programa).

Estar disponível para a implantação de novas atividades e ter flexibilidade são variáveis fundamentais, que apareceram nesta pesquisa, para concretizar a intersetorialidade. Isso porque a desenvoltura, a sensibilidade e a capacidade de mobilizar outras pessoas indica que a rede se potencializa coletivamente com atores que desejam fazer e que vão além das tarefas de rotina já estabelecidas. Assim, a rede intersetorial se faz com pessoas sensíveis, engajadas em uma perspectiva crítica da realidade.

Os profissionais entrevistados perceberam que a relação intersetorial, surgida da construção comum das Oficinas dos Pais, possibilitou ampliar o cuidado aos educandos e às famílias que procuravam a UBS, assim como ampliar suas percepções das situações e 
criar estratégias conjuntas de intervenção tendo os serviços como responsáveis pelo cuidado no território:

Eu acho válida, eu acho que facilita a gente estar articulado com a saúde, até porque a saúde tem um outro, um outro acompanhamento, digamos, da família. A gente tem o acompanhamento na parte educacional, pedagógica e a saúde conhece o outro lado, né. [...] E também porque lá, às vezes, a escola pode nem saber que uma família tá tendo algum problema com drogas. E isso aparece lá no posto. E a gente não sabe como vai fazer essa intervenção na escola. Às vezes, a gente leva uma situação de um aluno pro posto que a gente acha que tá com problema de aprendizagem ou por um outro motivo. "Mas, a família está tendo esse problema, tem algum usuário". Então tu já começa a ver um outro lado (Profissional da educação).

As pessoas chegam a cada serviço, seja da saúde ou da educação, com suas singularidades, no entanto, os serviços possuem seus próprios protocolos de atendimento e especialidades que não possibilitam ver a integralidade e algumas dimensões da pessoa, fragmentando-a. Quando dois serviços se conversam, amplia-se o olhar e percepção que se tem sobre a pessoa e o contexto, podendo a intervenção ser mais assertiva. E se cada serviço possuir seus próprios paradigmas para pensar, planejar e intervir, os quais podem ser antagônicos e complementares, e não contraditórios (Morin, 2002).

Quando dois ou mais serviços conseguem conversar, há troca de referências, paradigmas e conhecimentos sobre determinada pessoa ou território. Só a troca entre os serviços já produz efeitos, visto que provoca mudanças no serviço e na sua forma de trabalho. A relação, pactuação e ação entre dois serviços para determinado fim mais que duplica os efeitos, uma vez que o todo é mais que a soma das partes (Morin, 2002).

\section{Limites para construir a articulação intersetorial entre a saúde e a educação}

Os principais limites para concretização da articulação intersetorial relatados tanto por profissionais da saúde, quanto da educação e multiplicadores foram: questões políticas, pessoalização das relações intersetoriais, dificuldade de compreender o significado de intersetorialidade, demanda de trabalho excessiva, falta de profissionais, falta de receptividade de um setor para o outro, entre outros.

O processo de pactuação entre os setores das políticas de saúde e educação municipais teve a participação do coordenador nacional de saúde mental, com o objetivo de contratuar com as secretarias a implantação do programa de prevenção ao uso de drogas. No entanto, ocorreram diversas dificuldades nesse processo, conforme a fala do profissional da saúde:

A dificuldade que a gente tem aqui é que politicamente a saúde e a educação aqui não conversam. E isso é muito sério. Isso é muito, muito sério porque na hora de fazer a relação intersetorial, ela não vai também. Que é uma resposta do que já vem acontecendo no município. [...] E aí isso era algo que gerava instabilidade nas escolas (Profissional da gestão federal).

Os conflitos entre as secretarias ressoaram nas relações entre os serviços da ponta, uma vez que são delas que saem as diretrizes, determinações e apoios. De que maneira um gestor pode solicitar que um profissional se relacione com outro setor, se ele mesmo tem dificuldade de realizar o diálogo? Parece haver uma incoerência que, possivelmente, enfraquece os laços entre a educação e a saúde, entre as escolas e as UBS.

Outra dificuldade relatada pelos entrevistados foi a pessoalização dos projetos nos diversos setores, ou seja, cada setor escolheu um profissional para fazer a articulação intersetorial e o projeto, por vezes, deixou de ser da equipe.

E aí nisso que eu chego aqui, de fato muito organizado [o PSE], só que ele é bem personificado. Então, isso ajuda, mas tem a contrapartida. Ajuda porque você sabe com quem você precisa falar, mas tem hora que você só fala com essa pessoa. [...] Porque ele deixa de ser uma proposta territorial pra ser uma proposta individual. Então, essa é uma dificuldade que a gente tem (Profissional da gestão federal).

Retomando a Figura, os profissionais transitam entre os setores, o território e os pontos de intersecção, que constituem a relação intersetorial. O PSE 
e o programa de prevenção ao uso de drogas, nesse sentido, são programas intersetoriais, de responsabilidade tanto das escolas, quanto das UBS. O fato de ter alguém que coordena e organiza os programas em cada setor não parece ser o problema, mas sim a concentração da responsabilidade em uma única pessoa pelos programas e pela ação intersetorial. Essa pessoa coordenadora é fundamental como uma referência que promove a corresponsabilização de diversos trabalhadores. Esta parece ser uma condição para que se concretize a intersetorialidade, no entanto, identificou-se as dificuldades de atuar conjuntamente, por parte dos gestores e dos profissionais:

[...] nesse momento eu vejo uma tensão aí na direção das Secretarias Municipais, pois veio um representante de uma das Secretarias e disse: "A saúde que vai conduzir esse negócio". Um grifo no meu "vai". Numa voz autoritária, determinando uma tarefa pra saúde, fugindo totalmente da compreensão de que a saúde tá vindo na escola realizar uma ação intersetorial, conjunta. Tipo assim, "Educação faz as aulas do programa, saúde faz a oficina, cada um fica pro seu lado" (multiplicador do programa).

A entrevistada apontou, em seu relato, um dado importante para a implantação do programa e o trabalho em rede, qual seja, a compreensão da práxis da intersetorialidade por parte dos gestores. Se os gesto- res não têm conhecimento teórico-prático e disposição política para a atuação intersetorial, isso pode comprometer toda a implantação de uma política pública dessa natureza, pois será realizada a ação na direção multissetorial ou multiprofissional, ou seja, setores trabalhando com a mesma demanda justaposta e não compartilhada.

Constatou-se também a dificuldade de compreensão de profissionais das UBS e das escolas sobre a proposta intersetorial.

A dificuldade que eu vejo é do professor compreender a saúde dentro da escola. Eles sentem como se fossem intrusos dentro da escola e então recepcionam muito mal os nossos colegas da saúde e falta essa compreensão nessa rede de proteção (Profissional da educação).

Talvez esse seja um dos reflexos destes posicionamentos, pois os gestores parecem não conduzir suas práticas em direção da intersetorialidade e isso se revela nas dificuldades cotidianas de relação entre a secretaria de saúde e a secretaria de educação.

A proposta da intersetorialidade é que os serviços trabalhem conjuntamente e compartilhadamente com a mesma demanda. No Quadro, realizado a partir dos estudos deVasconcelos (2013), Mendes, Lewgoy e Silveira (2008) e Augusto et al. (2004), pode-se comparar as diferenças dos paradigmas multissetorial e intersetorial.

Quadro

Paradigmas Multissetorial x Intersetorial.

\begin{tabular}{|c|c|c|}
\hline & Multissetorial & Intersetorial \\
\hline Conceito & $\begin{array}{l}\text { Saberes técnico-científicos } \\
\text { setoriais no planejamento e } \\
\text { execução de políticas públicas } \\
\text { específicas }\end{array}$ & $\begin{array}{l}\text { Articulação dos saberes técnico-científicos } \\
\text { e populares no planejamento, execução e } \\
\text { avaliação de políticas públicas }\end{array}$ \\
\hline Forma de organização & $\begin{array}{l}\text { Os setores se reúnem } \\
\text { pontualmente }\end{array}$ & Os setores se reúnem permanentemente \\
\hline Agentes da ação & Representantes personificados & Representantes institucionais \\
\hline Relação entre setores & $\begin{array}{l}\text { Leva em consideração apenas a } \\
\text { finalidade de cada setor }\end{array}$ & $\begin{array}{l}\text { Leva em consideração as fragilidades e } \\
\text { potencialidades dos setores envolvidos }\end{array}$ \\
\hline $\begin{array}{l}\text { Construção de políticas } \\
\text { públicas }\end{array}$ & $\begin{array}{l}\text { Simples devido à relação frágil } \\
\text { entre os setores }\end{array}$ & $\begin{array}{l}\text { Complexa devido à grandiosidade das } \\
\text { relações entre os setores envolvidos }\end{array}$ \\
\hline Finalidade & $\begin{array}{l}\text { Desenvolvimento social através } \\
\text { políticas fragmentadas }\end{array}$ & $\begin{array}{l}\text { Desenvolvimento social através de } \\
\text { políticas integradas e integradoras }\end{array}$ \\
\hline Efeitos & Restrito & Amplo, sinérgico e complexo \\
\hline
\end{tabular}

Fonte: Elaboração das autoras (2014). 
O desconhecimento e baixo compromisso dos gestores e profissionais com a intersetorialidade pode produzir efeitos que se materializam como ações, na prática, multissetoriais. Identificou-se nas falas de alguns dos entrevistados a desvalorização das práticas intersetoriais e a compreensão equivocada de práticas ampliadas para além dos muros da escola ou da UBS.

Assim, um discurso que a unidade de saúde teme dizer: "Hoje fulano [profissional da saúde] não trabalha, não está trabalhando porque ele foi para a escola. Hoje ele não trabalha porque foi para o território". E isso eu já ouvi em outras unidades e referindo-se até a agente comunitário, que tem um trabalho de rua, que precisa sair, não é dentro da porta fechada (multiplicador do programa).

No modelo de saúde ampliado e preconizado pela política de atenção básica, espera-se que os profissionais transitem pelo território, conheçam a organização social da comunidade, reconheçam as lideranças comunitárias, os equipamentos sociais, áreas de risco, de lazer, os serviços, condições de moradia, renda familiar, saneamento, alfabetização, escolaridade, cultura, clima, entre outros (Brasil, 2006).

\section{Considerações finais}

Esse artigo teve como objetivo analisar as percepções dos profissionais e gestores da saúde e educação sobre a articulação intersetorial para a implantação de um programa de prevenção ao uso de drogas.

Na prática tradicional que atende à demanda de pessoas com algum agravo de saúde já identificado, focando na doença e no cuidado médico dentro da UBS, é impossível um cuidado baseado no território, nas ações de saúde e mais ainda na intersetorialidade. A UBS, ao realizar o planejamento, execução e avaliação das suas ações em saúde requer relação direta com o território e a intersetorialidade.

Constatou-se a importância do processo de pactuação nos serviços e escolas, ou seja, um processo de esclarecimento e negociação que informe a equipe de saúde sobre o programa, como ele acontece, quem participa, quando participa, as atividades que precisam ser realizadas, o tempo para realizar essas ações. Percebeu-se que essa etapa é primordial para o êxito das atividades de implantação de um programa dessa natureza; também, ao mesmo tempo, essas dificuldades revelam a forma de trabalhar das equipes de saúde, sua fragmentação e pouca implicação com o trabalho fora das UBS. Um processo de pactuação mais longo poderia facilitar a institucionalização do programa.

Outra dificuldade para concretizar a intersetorialidade é a demanda excessiva de trabalho no próprio serviço e a percepção dos profissionais de que esta é um encargo a mais. Logo, faz-se necessário que os coordenadores do programa, juntamente com as instâncias de gestão, tanto da saúde como da educação pensem em estratégias para que os profissionais envolvidos, tenham respaldo das equipes e atribuam sentido à sua prática profissional, quando de sua execução.

A demanda excessiva de trabalho desses profissionais, que apareceu como uma variável que intervém na prática do programa, também pode estar relacionada à falta de profissionais, sendo esta uma outra dificuldade para estabelecer a intersetorialidade. A escassez de pessoas nos serviços e instituições, destes setores, compromete o funcionamento e a organização dos mesmos, pois acaba restringindo as ações e intervenções, sobrecarregando alguns profissionais.

Identificou-se, nesta pesquisa, que a intersetorialidade implementada pela realização conjunta de ações em um programa preventivo foi percebida pelos profissionais da saúde e educação como uma estratégia para ampliar o cuidado à comunidade, o que consolida a práxis da saúde de uma forma ampliada.

No entanto, ainda se impõe como desafio superar diferenças políticas e ideológicas entre gestões dos diferentes setores envolvidos, que se desdobram nas dificuldades de alguns profissionais da saúde e educação não compreenderem o significado de intersetorialidade, implementando, na prática, uma multissetorialidade. Tal compreensão parece afetar o processo de trabalho dos demais profissionais e o planejamento e ações dos serviços.

A estratégia utilizada pelo MS de solicitar a realização conjunta de atividades no programa de prevenção aos problemas relacionados uso de drogas nas escolas participantes foi potencializadora de ações intersetoriais concretas, muitas vezes não ocorridas antes desta "provocação". Por outro lado, desvelou as dificuldades concretas que no município e nos territórios das escolas a articulação entre diferentes setores enfrentava, o que provocou gestores e profissionais a repensarem suas concepções e práticas. 
Como foi verificado acima, as questões políticas intervêm no desenvolvimento de ações intersetoriais em termos da implementação de uma política pública. Este estudo foi realizado em uma única cidade, sendo que o programa em estudo foi implementado, na verdade, em várias cidades e estados, visando uma futura aplicação em larga escala no território brasileiro. Sendo assim, as especificidades políticas desse município podem impor especificidades de relacionamento entre os diferentes setores estudados que poderiam ser diferentes em outras cidades e estados e com mais autores envolvidos, exigindo cuidado na generalização das afirmações.
Do mesmo modo, seria interessante um estudo que desse continuidade na avaliação das relações intersetoriais produzidas pela implementação do Programa Preventivo em estudo, na medida em que o macroprojeto teve continuidade nos anos seguintes. Sendo assim, os dados limitam-se ao primeiro ano da experiência discutida, sendo que novos dados certamente estão sendo produzidos por esta experiência de implementação intersetorial desta política pública preventiva em larga escala. Também seria interessante cruzar dados da avaliação da intersetorialidade nos resultados obtidos nos desfechos principais do programa preventivo, ou seja, na mudança do padrão do uso de drogas dos adolescentes.

\section{Referências}

Andrade, L. O. M. (2006). A saúde e o dilema da intersetorialidade. São Paulo, SP: Hucitec.

Augusto, T. G. S. et al (2004). Interdisciplinaridade: concepções de professores da área ciências da natureza em formação em serviço. Ciência e Saúde, 10(2), 277-289.

Bardin, L. (2009). Análise de conteúdo (5a ed., L. A. Reto, A. Pinheiro, trad.). Lisboa: Edições 70.

Brasil. (2003). Ministério da Saúde. A política do Ministério da Saúde para atenção integral a usuários de álcool e outras drogas. Brasília, DF: Ministério da Saúde.

Brasil. (2004).. Ministério do Desenvolvimento Social e Combate à Fome. Secretaria Nacional de Assistência Social. Política Nacional de Assistência Social: PNAS/2004: norma operacional básica NOB/SUAS. Brasília, DF: o autor.

Brasil. (2006). Ministério da Saúde. Secretaria de Atenção à Saúde. HumanizaSUS: documento base para gestores e trabalhadores do SUS (3a ed.). Brasília, DF: o autor.

Bronfenbrenner, U. (1996). A ecologia do desenvolvimento humano: experimentos naturais e planejados. Porto Alegre, RS: Artes Médicas.

Canoletti, B., \& Soares, C. B. (2005). Programas de prevenção ao consumo de drogas no Brasil: uma análise da produção científica de 1991 a 2001. Interface (Botuctu), 9(16), 115-129. https://dx.doi.org/10.1590/S141432832005000100010

Carlini, E. A., Noto, A. R., Sanchez, Z. M., Carlini, C. M. A., Locatelli, D. P., Abeid, L. R. et al. (2010). VI levantamento nacional sobre o consumo de drogas psicotrópicas entre estudantes do ensino fundamental e médio das redes pública e privada de ensino das 27 capitais brasileiras. São Paulo, SP: Cebrid.

Faggiano, F, Richardson, C., Bohrn, K., Galanti, M. R. (2007). A cluster randomized controlled trial of school-based prevention of tobacco, alcohol and drug use: the EU-Dap design and study population. Preventive Medicine, 44(2):170-3. https://doi.org/10.1016/j.ypmed.2006.09.010

Faggiano, F., Vigna-Taglianti, F., Burkhart, G., Bohm, K., Cuoo, L., Gregori, D. et. al. (2010). The effectiveness of a school-based substance abuse prevention program: 18-month follow-up of the EU-Dap cluster randomized controlled trial. Drug and Alcohol Dependence, 108(1-2), 56-64. https://doi.org/10.1016/j.drugalcdep.2009.11.018

Figueiredo, T. A. M., Machado, V. L.T., \& Abreu, M. M. S. (2010). A saúde na escola: um breve resgate histórico. Ciência \& Saúde Coletiva, 15(2):397-402. https://doi.org/10.1590/S1413-81232010000200015

Instituto Brasileiro de Geografia e Estatística (2013). Pesquisa Nacional de Saúde na escola. Rio de Janeiro, RJ: o autor. Recuperado de http://biblioteca.ibge.gov.br/visualizacao/livros/liv64436.pdf

Instituto Nacional sobre el Abuso de Drogas. (2004). Cómo prevenir el uso de drogas em los niños y los adolescentes: una guía con base científica para padres, educadores y líderes de la comunidad (2a ed.). Bethesda: o autor. Recuperado de https://www.drugabuse.gov/sites/default/files/redbook_spanish.pdf 
Mcnamee, S. (2010). Reserch as social construction: transformative inquiry. Saúdee Transformação Social, 1(1), 9-19. Recuperado de http://incubadora.periodicos.ufsc.br/index.php/saudeetransformacao/article/view/418/477

Martinhago, F. \& Oliveira, W.F. (2012). A prática profissional nos Centros de Atenção Psicossocial II (CAPS II), na perspectiva dos profissionais de saúde mental de Santa Catarina. Saúde em Debate, 36(95),583-594. https://doi. org/10.1590/S0103-11042012000400010

Medeiros P. F. P., Cruz J., Schneider, D. R., Sanudo, A., \& Sanchez, Z. M. (2016). Process evaluation of the implementation of the Unplugged Program for drug use prevention in Brazilian schools. Substance Abuse Treatment, Prevention, and Policy, 11(2): 1-11. https://doi.org/10.1186/s13011-015-0047-9

Mendes, J. M. R., Lewgoy, A. M. B., \& Silveira, E. C. (2008). Saúde e interdisciplinaridade: mundo vasto mundo. Ciência \& Saúde, 1(1). 24-32. https://doi.org/10.15448/1983-652X.2008.1.3864

Minayo, M. C. S. (1999). O desafio do conhecimento: pesquisa qualitativa em saúde. São Paulo, SP: Hucitec.

Morin, E. (2002). Ciência com consciência (6a ed.). Rio de Janeiro, RJ: Bertrand Brasil.

Organização Panamericana de la Salud - OPAS. (2001). Enfoque de habilidades para a vida para um de desenvolvimento saudável de crianças e adolescentes. Washington, DF: o autor.

Paiva, F. S., \& Rodrigues, M. C. (2008). Habilidades de vida: uma estratégia preventiva ao consumo de substâncias psicoativas no contexto educativo. Estudos e Pesquisas em Psicologia, 8(3), 672-684. Recuperado de http://pepsic. bvsalud.org/pdf/epp/v8n3/v8n3a09.pdf

Paula, K. A.. Palha, P. F., \& Protti, S. T. (2004). Intersetorialidade: uma vivência prática ou um desafio a ser conquistado? O discurso do sujeito coletivo dos enfermeiros dos núcleos de saúde da família do Distrito Oeste - Ribeirão Preto. Interface (Botucatu), 8(15), 331-348. https://doi.org/10.1590/S1414-32832004000200011

Sanchez, Z. M., Sanudo, A., Andreoni, S., Schneider, D., Pereira, A. P., \& Faggiano, F. (2016). Efficacy evaluation of the school program Unplugged for drug use prevention among Brazilian adolescents. BMC Public Health, 16(1), 1206. https://doi.org/10.1186/s12889-016-3877-0

Schneider, D. R., Oltramari, L., Budde, C., Silveira, A. L., Silveira, S. (2016). A clínica na comunidade: uma experiência de intervenção intersetorial para adolescentes em situação de vulnerabilidade psicossocial. Cadernos Brasileiros de Saúde Mental, 8(18), 68-80. Recuperado de http://incubadora.periodicos.ufsc.br/index.php/cbsm/ article/view/4036/4707

Sloboda, Z., Stephens, R. C., Stephens, P. C., Grey, S. F., Teasdale, B., Hawthronrne, R. D. et al. (2009). The adolescent substance abuse prevention study: a randomized field trial of a universal substance abuse prevention program. Drug and Alcohol Dependence, 102(1-3), 1-10. https://doi.org/10.1016/j.drugalcdep.2009.01.015

Sloboda, Z., \& Petras, H. (2014). Defining prevention science. New York, NY: Springer.

Vasconcelos, E. M. (2013). Complexidade e pesquisa interdisciplinar: epistemologia e metodologia operativa (6a ed.). Petrópolis, RJ: Vozes.

Girlane Mayara Peres

Departamento de Psicologia da Universidade Federal de Santa Catarina, Florianópolis - SC. Brasil.

E-mail: mayperes@gmail.com

\section{Tania Maris Grigolo}

Doutora em Psicologia Clínica e Cultura pela Universidade de Brasília, Brasília - DF. Brasil.

E-mail: taniamgrigolo@gmail.com

\section{Daniela Ribeiro Schneider}

Professora do Departamento de Psicologia da Universidade Federal de Santa Catarina. Doutorado em Psicologia Clínica pela Pontifícia Universidade Católica de São Paulo, São Paulo - SP. Brasil. Pós-Doutorado pela Universidad de Valencia, Valência. Espanha.

E-mail: danischneiderpsi@gmail.com 
Endereço para envio de correspondência:

Mestrado Profissional em Saúde Mental e Atenção Psicossocial, Centro de Ciências da Saúde. Campus Reitor João David Ferreira Lima, s/n - Trindade, Florianópolis - SC, 88040-900

Recebido 29/08/2016

Reformulado 28/03/2017

Aprovado 03/08/2017

Received 08/29/2016

Reformulated $03 / 28 / 2017$

Approved 08/03/2017

Recibido 29/08/2016

Reformulado 28/03/2017

Aceptado 03/08/2017

Como citar: Peres, G. M., Grigolo, T. M., \& Schneider, D. R. (2017). Desafios da Intersetorialidade na

Implementação de Programa de Prevenção ao Uso Abusivo de Drogas. Psicologia: Ciência e Profissão, 37(4), 869-882. https://doi.org/10.1590/1982-3703003272016

How to cite: Peres, G. M., Grigolo, T. M., \& Schneider, D. R. (2017). Challenges of the Intersectoral Approach in the Implementation of a Program for the Prevention of Drug Abuse. Psicologia: Ciência e Profissão, 37(4), 869-882. https://doi.org/10.1590/1982-3703003272016

Cómo citar: Peres, G. M., Grigolo, T. M., \& Schneider, D. R. ( (2017). Desafíos del Enfoque Intersectorial en la Implementación de un Programa de Prevención del Uso Abusivo de Drogas. Psicologia: Ciência e Profissão, 37(4), 869-882. https://doi.org/10.1590/1982-3703003272016 